\title{
Evaluation of wheelchair resistive forces during straight and turning trajectories across different wheelchair configurations using free-wheeling coast-down test
}

\author{
Jui-Te Lin, MS; ${ }^{{ }^{*}}$ Morris Huang, BSME; ${ }^{\mathbf{2}}$ Stephen Sprigle, PhD, PT $^{\mathbf{1}}$ \\ Departments of ${ }^{1}$ Applied Physiology and ${ }^{2}$ Bioengineering, Georgia Institute of Technology, Atlanta, GA
}

\begin{abstract}
The purpose of this study was to develop a simple approach to evaluate resistive frictional forces acting on manual wheelchairs (MWCs) during straight and turning maneuvers. Using a dummy-occupied MWC, decelerations were measured via axle-mounted encoders during a coast-down protocol that included straight trajectories and fixed-wheel turns. Eight coast-down trials were conducted to test repeatability and repeated on separate days to evaluate reliability. Without changing the inertia of the MWC system, three tire inflations were chosen to evaluate the sensitivity in discerning deceleration differences using effect sizes. The technique was also deployed to investigate the effect of different MWC masses and weight distributions on resistive forces. Results showed that the proposed coast-down technique had good repeatability and reliability in measuring decelerations and had good sensitivity in discerning differences in tire inflation, especially during turning. The results also indicated that increased loading on drive wheels reduced resistive losses in straight trajectories while increasing resistive losses during turning. During turning trajectories, the presence of tire scrub contributes significantly to the amount of resistive force. Overall, this new coast-down technique demonstrates satisfactory repeatability and sensitivity for detecting deceleration changes during straight and turning trajectories, indicating that it can be used to evaluate resistive loss of different MWC configurations and maneuvers.
\end{abstract}

Key words: coast-down test, friction, mass distribution, pneumatic tire, rehabilitation, rolling resistance, tire pressure, tire scrub, turning resistance, wheelchair, wheeled mobility.

\section{INTRODUCTION}

When propelling a manual wheelchair (MWC), users apply torque to drive wheels (DWs) in order to achieve a specific maneuver. The magnitude of this propulsion torque depends on the kinematics of the maneuver and the characteristics of the user-MWC system. On an MWC with greater frictional resistance, the user needs to exert greater instantaneous force and total effort while completing a maneuver [1-3]. Greater effort can lead to difficulty in achieving desired speeds, a higher probability of fatigue over long bouts of mobility, and difficulty negotiating inclines. Over time, the accumulation of this greater effort can increase the potential for injury in the upper limbs, a complication in MWC users that has been well-described for many years [4-6].

\footnotetext{
Abbreviations: ANOVA $=$ analysis of variance, $\mathrm{CoM}=$ center of mass, $\mathrm{CV}=$ coefficient of variation, $\mathrm{DW}=$ drive wheel, ICC = intraclass correlation coefficient, ISO = International Organization for Standardization, MWC = manual wheelchair, $\mathrm{SD}=$ standard deviation.

*Address all correspondence to Jui-Te Lin, MS; Department of Applied Physiology, Georgia Institute of Technology, 555 14th St NW, Atlanta, GA 30332; 404-894-3986; fax: 404-894-9982. Email: jlin79@gatech.edu

http://dx.doi.org/10.1682/JRRD.2014.10.0235
} 
Improving wheelchair propulsion has motivated a substantial body of research, including studies on mechanical systems and components with regard to inertia and resistive loss [7-8]. When moving over ground, resistive energy losses occur because of a combination of rolling resistance, bearing resistance, tire scrub, and other frictional factors such as drag and frame flexion [2,9]. Researchers have used a variety of techniques to characterize these losses.

The resistive losses of the wheelchair tires and entire wheelchair systems have been measured experimentally using component-level analysis [10], treadmill [11-12], dynamometer [13], and roll-down tests [8,14-16]. Kauzlarich and Thacker demonstrated via both component and system analysis that rolling resistance is related to tire material, wheel radius, profile radius, and load on the wheel base [10]. For a typical polyurethane solid tire and a $200 \mathrm{lb}$ occupant, they calculated a rolling resistance of $13.4 \mathrm{~N}$ [10]. Gordon et al. [11] and Kwarciak et al. [13] measured rolling resistances of wheelchair DWs using a treadmill and dynamometer, respectively. These approaches are able to isolate resistive losses due to a single component (e.g., DWs) but were limited to testing on only the rolling surfaces of the respective equipment. Free-wheeling rolldown tests have been used to measure resistive losses of the entire wheelchair system and to study the effect of different rolling surfaces. For example, Hoffman et al. used three timing sensors to measure decelerations on different wheelchair frames, wheel combinations, and ground surfaces [15]. Both Bascou et al. [14] and Sauret et al. [16] developed a mechanical model of MWC deceleration to describe the effect of mass distribution and ground surface on rolling resistance properties. These studies concluded that wheelchair configurations and surface conditions can significantly affect the rolling resistance [14-16]. While these coast-down tests have been capable of characterizing overall rolling resistance, the methods have been constrained to straight trajectories. As a result, they are unable to capture the resistive forces from tire scrub associated with wheelchair turning maneuvers.

During turning maneuvers, the finite tire surface contacting the ground surface distorts as the wheels turn relative to the ground. This distortion is accompanied by a restoring force, termed sideslip friction or scrub torque. The magnitude of this force depends on many properties, such as the load applied, contact area, and sideslip angle [17]. Sideslip angle is the angle between the wheel orientation and the direction of its velocity and is typically small for both casters and DWs during steady-state fixed-radius turning. However, during instances where the turning radius changes and the casters swivel with respect to the wheelchair frame, sideslip angles of the casters become very large, elevating scrub torque substantially. Therefore, in all instances of turning, the scrub torque of the casters and DWs contributes to the overall resistive force.

Kauzlarich et al. developed a wheel model to evaluate different caster designs on caster shimmy and turning resistance [18]. The turning resistance of casters was quantified by measuring caster turning torque while applying normal loads via a drill press. By constraining one of the DWs to pivot without rolling, system-level turning resistance was further evaluated by measuring the pivot torque necessary to initiate turning. The results have shown that casters with grooved tires $(0.5 \mathrm{in}$.) had 10 percent greater turning resistance than casters with ungrooved tires [18]. In addition, an estimated $7 \mathrm{~N}-\mathrm{m}$ is required to initiate turning when $300 \mathrm{~N}$ are loaded onto each DW [18]. Frank and Abel also studied turning resistance by measuring the torque required to pivot casters with diameters between 10 and $20 \mathrm{~cm}$ [19]. Over a load range of 50 to $300 \mathrm{~N}$, turning resistance for a caster spanned a range from 0.3 to $2.8 \mathrm{~N} \bullet \mathrm{m}$ [19]. Caspall et al. used these results to estimate that $8.75 \mathrm{~N} \bullet \mathrm{m}$ is needed to swivel wheelchair casters loaded to $100 \mathrm{~N}$, which was based upon a 20/80 percent caster-to-DW weight distribution for a $90 \mathrm{~kg}$ user and a $12 \mathrm{~kg}$ wheelchair [2]. These results document the resistive losses that occur when casters swivel and underscore the need to measure resistive losses of a wheelchair system during turning maneuvers in addition to straight trajectories. However, these studies have yet to quantify the effect of different wheelchair configurations and designs on overall resistive torque while turning.

In daily life, MWC users tend to move in relatively short bouts of movements that include turning [20]. Therefore, it is important to characterize resistive loss during both straight and turning maneuvers and how these losses vary across different MWC designs and configurations. The objective of this study was to design a reliable and valid approach to evaluate overall MWC resistive losses by measuring decelerations during straight and turning trajectories and calculating the resistive forces based on the deceleration profiles. To evaluate the sensitivity of the proposed technique in discerning differences, MWCs were tested with different tire inflations, masses, and mass distributions. 


\section{METHODS}

\section{Test Equipment and Instrumentation}

\section{Test Mannequin}

A $76 \mathrm{~kg}$ International Organization for Standardization (ISO) 7176-11 dummy was used as the MWC occupant during straight and fixed-wheel coast-down tests. A mannequin was chosen to avoid the confounding factors of body movement and postural changes that could be present when using human subjects [21]. This mannequin was configured to have a similar fore-aft location of the dummy center of mass (CoM) as the new ISO standard (220 mm from the dummy's back support reference plane) [22].

\section{Test Surface}

All coast-down tests were conducted on an indoor surface comprised of $12 \times 12$ in. linoleum tiles. The standardized coefficient of kinetic friction of the tile surface was found to be 0.54 using the Rehabilitation Engineering and Assistive Technology Society of North America's test procedure to characterize surfaces during wheelchair testing [23].

\section{Manual Wheelchair Configurations}

This study used the Aero Z (TiLite; Pasco, Washington) for all coast-down tests. The Aero $\mathrm{Z}$ had a mass of $12.1 \mathrm{~kg}$ and is coded as an ultralight MWC (K0005) by the Centers for Medicare and Medicaid Services [24]. The MWC was chosen based on its adjustability. The default MWC setup had 24 in. spoke wheels with $13 / 8$ in. light gray tread pneumatic tires (Primo Orion, Gallop Cycle Corp; Carson, California) and $5 \times 11 / 2$ in. urethane casters (EPIC, Frog Legs Inc; Ottumwa, Iowa) with aluminum forks (TiLite). The axle position was set at $7.6 \mathrm{~cm}$ forward of the backrest, resulting in 70 percent of the MWC mass on its DWs. To evaluate different resistive loss without changing system inertia, testing was performed at three DW tire inflations: 75 psi (100\%), 55 psi (75\%), and 38 psi (50\%). In order to evaluate the influence of mass and weight distribution on resistive loss, the MWC was reconfigured to have a similar mass (17.6 kg) and weight distribution (55\% loading on DWs) as a K0001 standard MWC, the Tracer EX2 (Invacare; Elyria, Ohio). Therefore, coast-down tests were used to measure the resistive losses of an MWC with two masses (12 vs $17.6 \mathrm{~kg}$ ) and two weight distributions (55\% vs $70 \%$ load- ing on DWs). We chose to test the same MWC with different configurations rather than different MWCs in order to better control for potential confounding factors such as bearing resistance, tire type, and frame flexion. This approach allowed for the differences in results to be attributed to the independent variables, namely tire inflation, mass, and weight distribution.

\section{System and Wheel Inertia}

In order to calculate the resistive forces that decelerate the rolling $\mathrm{MWC}$, inertial properties of the loaded MWC, wheels, and casters are required. Mass, yaw inertia of the MWC $\left(I_{G}\right)$, and the location of the CoM were measured experimentally using a device called the iMachine [25]. The device consists of a turntable mounted to a single axle. Load cells mounted on the turntable measure the mass and CoM of the MWC. Measuring the CoM distance from the rear axle makes it possible to calculate the caster-to-DW load-distribution of the MWC. An encoder measures rotation of the turntable, whose oscillations are damped by a spring of known stiffness, allowing calculation of rotational inertia from measured natural frequency. The rotational inertia of the DWs and casters was measured using a system based on the established Trifilar Pendulum [26-27], which measures the rotational inertia based on the mass and the frequency of oscillation.

\section{Manual Wheelchair Encoders}

Angular velocities of the DWs were measured by two axle-mount M-260 optical encoders (Encoder Products Co; Sagle, Idaho). These encoders were connected to a data acquisition system (LabJack U6, LabJack Corporation; Lakewood, Colorado), positioned under the seat, and operated at a $400 \mathrm{~Hz}$ sampling rate. A Windows tablet (Microsoft Corporation; Redmond, Washington) was used to store encoder data and provide power for the LabJack U6. Linear wheel velocity was calculated using Equation 1:

$$
v=R \omega,
$$

where $v(\mathrm{~m} / \mathrm{s})$ is the linear speed of the $\mathrm{DW}, \omega$ (radians $/ \mathrm{s}$ ) is the angular speed of the $\mathrm{DW}$, and $R(\mathrm{~m})$ is the radius of the DW. The instrumentation added $2 \mathrm{~kg}$ to the MWC and was positioned near the CoM such that it did not affect the system turning inertia. Figure 1 shows the setup of the measurement system. 


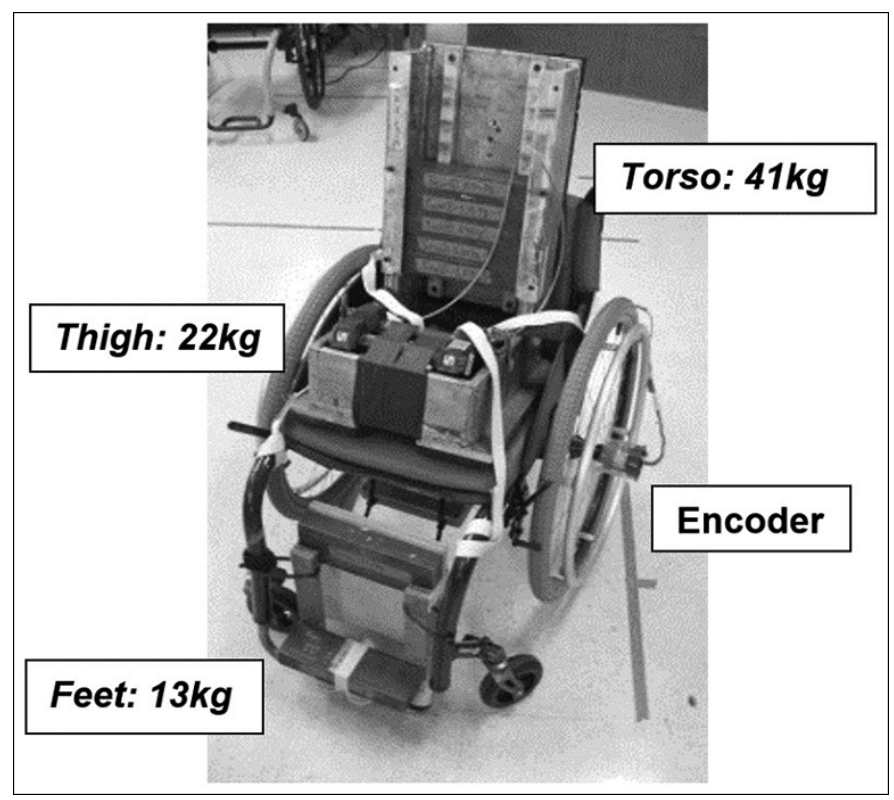

Figure 1.

Setup of tested manual wheelchair.

\section{Coast-Down Test}

A coast-down test was performed to calculate deceleration parameters during free-wheeling straight and turning motions. All testing occurred on a level tile floor that was cleaned before testing. According to previous studies, MWC users typically maneuver at speeds $<1 \mathrm{~m} / \mathrm{s}$ $[20,28]$, so speeds reflective of everyday mobility were selected for the coast-down procedure. A fixed-wheeled turn was achieved by engaging the wheel lock to one DW by a standard MWC lock. Both left and right turns were evaluated. Eight coast-down trials were conducted for each configuration by the same operator. The test protocol consisted of three phases:

1. Push phase: An operator pushed the MWC to a speed of approximately $1 \mathrm{~m} / \mathrm{s}$ during straight trajectories and $0.4 \mathrm{~m} / \mathrm{s}$ during turning trajectories. These target speeds were chosen to ensure that coast-down included the speed ranges for data analysis.

2. Release phase: The MWC was released at the same location and direction within each trajectory.

3. Free deceleration phase: DW velocities were measured as the MWC decelerated.

Deceleration values were calculated over targeted speed ranges (straight: $0.65-0.95 \mathrm{~m} / \mathrm{s}$; turning: $0.1-0.3 \mathrm{~m} / \mathrm{s}$ ).

\section{DATA ANALYSIS}

The summation of resistive losses includes rolling resistance, tire scrub, bearing resistance, frame flexion, gravity, and variable external resistances. For our purposes, all motion was assumed to take place over level ground. Furthermore, given relatively slow speeds $(<1 \mathrm{~m} /$ s) and use of the same MWC frame and wheels across trials, we assumed that the influence of aerodynamic drag and variable external resistance, such as bearing resistance, would be negligible [29]. Figure 2 illustrates the simplified frictional forces that must be overcome in both straight and turning given these assumptions. Drawing from the Sauret et al. model for MWCs [16], the deceleration and associated resistive forces for a straight coastdown can be described by Equation 2:

$$
\left(M_{s y s}+2 \frac{I_{d}}{R_{d^{2}}}+2 \frac{I_{c}}{R_{c}}\right) \ddot{\chi}=-2 \frac{\lambda_{d}}{R_{d}}\left(F_{N}\right)_{d}-2 \frac{\lambda_{c}}{R_{c}}\left(F_{N}\right)_{c},
$$

where $M_{\text {sys }}$ is the system mass; $\ddot{x}$ is the tangential acceleration of CoM; $I_{d}$ and $I_{c}$ are the inertias of the DWs and casters, respectively; $R_{d}$ and $R_{c}$ are the radii of the DWs and casters, respectively; $\left(F_{N}\right)_{d}$ and $\left(F_{N}\right)_{c}$ are the normal forces on the DWs and casters, respectively; and $\lambda_{d}$ and $\lambda_{c}$ are the DW and caster rolling resistance parameters (m), respectively, characterized by the fore-aft distance between the theoretical and actual centers of pressure in the wheel contact areas. Based on the small effect of the component inertias observed in Sauret et al.'s model simulations [16], it becomes possible to approximate the combined mass terms as the dominant system mass. Additionally, we can rewrite the normal force terms as rolling resistance, as shown in Equation 3:

$$
M_{s y s} \ddot{\chi}=-2\left(F_{R R}\right)_{d}-2\left(F_{R R}\right)_{c},
$$

where $\left(F_{R R}\right)_{d}$ and $\left(F_{R R}\right)_{c}$ are the rolling resistance forces of the DWs and casters, respectively.

Compared with straight trajectories, resistive torque during fixed-wheeled turns includes not only rolling resistance but also tire scrub [2,18]. In the case of the rolling DWs and casters, tire scrub arises from a sideslip force that is generated because of a discontinuity between the tire heading direction and direction of velocity, otherwise known as the sideslip angle [17]. However, for the purposes of the turning resistance model, the tire scrub associated with the casters will be considered negligible. Since 


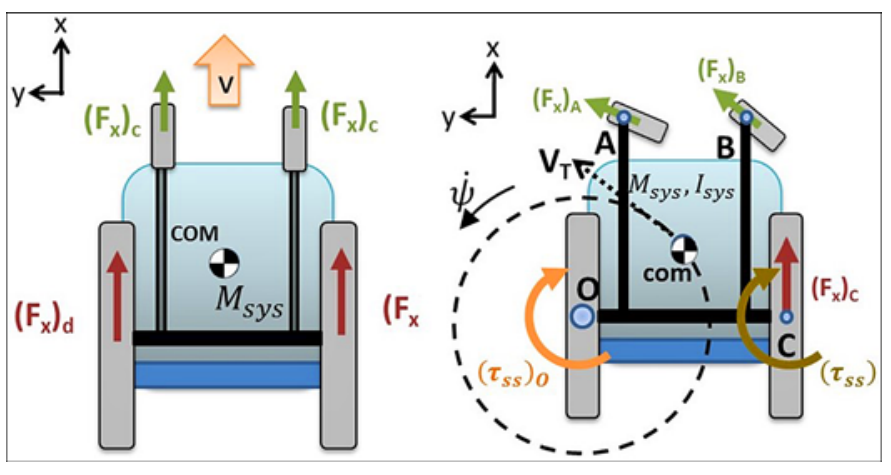

Figure 2.

Model of straight motion and fixed-wheel turns with resistance forces with resistive forces $(F)$ and tire scrub torques $(\tau)$. CoM = center of mass, $V_{T}=$ tangential velocity.

casters are linked to the MWC frame via vertical pin joints, the transmitted torques under ideal conditions are zero. Furthermore, during a turning coast-down test, the casters have become aligned with the radius of curvature, reducing the turning resistance that arises from the sideslip forces transmitted through the forks. The scrub torque of the fixed and pivoting DW is fundamentally different and is greater in magnitude than that of the casters and the rotating DW since the same contact patch is constantly undergoing shear. For example, the coast-down forces during a fixed-wheel left turn can be modeled as Equation 4:

$$
\begin{aligned}
& \mathrm{I}_{\text {turn }}\left(\frac{\ddot{x}}{r_{G / O}}\right)=\left(r_{A / O}\right) \times-\left(F_{R R}\right)_{A}+\left(r_{B / O}\right) \times-\left(F_{R R}\right)_{B}+ \\
& \left(r_{C / O}\right) \times-\left(F_{R R}\right)_{C}-\left(\tau_{s s}\right)_{C}-\left(\tau_{s s}\right)_{O},
\end{aligned}
$$

where $I_{\text {turn }}$ is the combined inertial terms $\left(\mathrm{kg} \bullet \mathrm{m}^{2}\right)$ of the system and its components during fixed-wheel turning; $\ddot{x}$ is the tangential acceleration of the CoM; $r_{G / O}, r_{A / O}$, $r_{B / O}$, and $r_{C / O}$ are the distances from the center of rotation to the CoM, left caster fork, right caster fork, and right DW, respectively; $\left(F_{R R}\right)_{A},\left(F_{R R}\right)_{B}$, and $\left(F_{R R}\right)_{C}$ are the rolling resistance forces of the left caster, right caster, and right DW, respectively; and $\left(\tau_{S S}\right)_{C}$ and $\left(\tau_{S S}\right)_{O}$ are the scrub torques of the rolling right DW and the fixed left DW, respectively. Note that the $I_{\text {turn }}$ term is heavily dominated by the system yaw inertia, $I_{G}$, adjusted by the parallel-axis theorem to be centered at point $O$ (the center of rotation) and represented by $I_{O}$, as shown in Equation 5.

$$
I_{o}=M_{G}+M_{\text {sys }}\left(r_{G / O}\right)^{2} \text {. }
$$

By applying the same simplifying assumption for Equation 3 that allows us to treat component rotational inertias as being negligible, Equation $\mathbf{4}$ can be reduced as shown in Equation 6.

$$
\begin{aligned}
& \mathrm{I}_{O}\left(\frac{\ddot{x}}{r_{G / O}}\right)=\left(r_{A / O}\right) \times-\left(F_{R R}\right)_{A}+\left(r_{B / O}\right) \times-\left(F_{R R}\right)_{B}+ \\
& \left(r_{C / O}\right) \times-\left(F_{R R}\right)_{C}-\left(\tau_{s s}\right)_{C}-\left(\tau_{s s}\right)_{O}
\end{aligned}
$$

Generally, overall resistive loss during straight trajectories is mainly contributed by wheel rolling resistance (Equation 3), whereas both rolling resistance and tire scrub contribute to overall resistive loss during fixedwheel turns (Equation 6). Therefore, tire sideslip force and its resultant scrub torque is the distinguishing resistive loss factor between these two maneuvers.

To capture CoM decelerations, time-series velocity data from both DWs were captured and low-pass filtered at $20 \mathrm{~Hz}$. During the straight coast-down test, the averaged velocity values from the left $\mathrm{DW}\left(V_{L D}\right)$ and right $\mathrm{DW}$ $\left(V_{R D}\right)$ were used to represent CoM velocity $\left(V_{\mathrm{CoM}}\right)$. In turning trajectories, averaging $V_{L D}$ and $V_{R D}$ represented the tangential velocity $\left(V_{T}\right)$ of CoM. Deceleration during each trial was determined using linear regression. The coefficient of determination $\left(r^{2}\right)$ in all linear regression models was $>0.96$. Figure 3 shows a linear regression of an example of velocity versus time during coast-down.

Postprocessing of all deceleration values was performed via a custom MATLAB code (The MathWorks Inc; Natick, Massachusetts). Repeated test variation is represented by the coefficient of variation (CV) and standard deviation (SD). To support future studies in coast-down

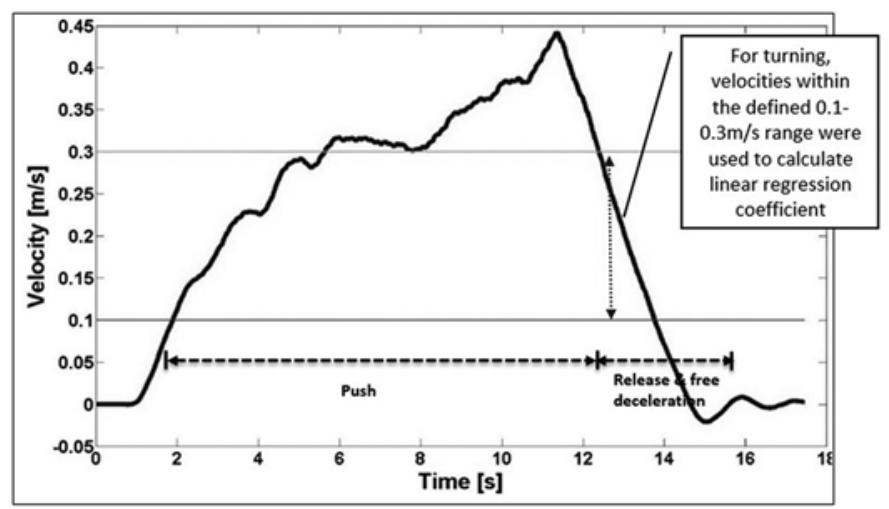

Figure 3.

Example of time versus velocity response during fixed-wheel turning coast-down test. 
tests, we analyzed the minimum number of repeated tests need to provide a reliable estimate of deceleration. The Spearman-Brown Prophecy Formula was used to predict the number of tests required to achieve good repeatability (alpha $=0.9$ ).

To demonstrate test-retest reliability of the protocol, one operator repeated experiments on 2 different days. Reliability was characterized by the intraclass correlation coefficient (ICC) using a two-factor mixed-effects model and type consistency. Since the coast-down testing sequence on day 1 was not controlled to match the testing sequence on day 2 , deceleration values were randomized three times for each trajectory task before running the reliability test. The averaged ICC value was calculated for the final report. Decelerations for the chairs with different masses and weight distributions during both trajectories were tabulated and graphed using means and confidence intervals. Overall resistive force in a straight motion and resistive torque in turning were later calculated based on the measured decelerations as well as respective system mass or inertia. These data provided the most direct evaluation of differences with the ability to judge meaningfulness across MWC designs.

The test sensitivity was assessed by its ability to distinguish differences in resistive losses across different MWC configurations, specifically DW inflation levels, masses, and weight distributions. In a strict sense, testing multiple MWC configurations over multiple trials does not permit the use of analysis of variance (ANOVA) to infer differences due to the violation of the assumption of independence. However, in deference to convention, simple univariate ANOVA results are reported for the straight and turning maneuvers using $p<0.05$ to define statistical significance. Percent differences and effect sizes were calculated to fully describe differences in decelerations across configurations.

\section{RESULTS}

Table 1 shows information of inertia and weight distribution of the occupied MWC measured by the iMachine. Across all configurations, the repeatability of deceleration values was very good, with CVs less than 5.3 percent for all coast-down trials (Table 2). The result of the SpearmanBrown Prophecy Formula analysis suggested that three repeated trials were sufficient to achieve a reliability of 0.99 for all MWC configurations. Additionally, a high degree of
Table 1.

Manual wheelchair mass, inertia, and weight distribution with $76 \mathrm{~kg}$ mannequin.

\begin{tabular}{cccc}
\hline $\begin{array}{c}\text { Mass } \\
\mathbf{( k g )}\end{array}$ & $\begin{array}{c}\text { Axle Position } \\
\mathbf{( c m )}\end{array}$ & $\begin{array}{c}\mathbf{I}_{\boldsymbol{G}} \\
\left(\mathbf{k g} \bullet^{\mathbf{2}} \mathbf{)}\right.\end{array}$ & $\begin{array}{c}\text { Load on Drive } \\
\text { Wheels (\%) }\end{array}$ \\
\hline 12.1 & 7.6 & 4.96 & 70 \\
17.6 & 7.6 & 4.97 & 70 \\
12.1 & 4.5 & 4.64 & 55 \\
17.6 & 4.5 & 4.65 & 55 \\
\hline
\end{tabular}

${ }^{*}$ Horizontal distance from backrest to axle position.

$I_{G}=$ inertia of manual wheelchair system about vertical axis of center of mass.

reliability was found between 2 days by the same operator (ICC $=0.959$ ). The mean \pm SD between-day variation for decelerations was $0.001 \pm 0.006 \mathrm{~m} / \mathrm{s}^{2}$.

By using the same mass and axle position, Table 2 and Figure 4 show the MWC decelerations with three different inflation levels. No differences in deceleration values existed across left and right turning trajectories ( $p=$ 0.14 ), so averaged turning deceleration values are reported. Decelerations were greater during turning trajectories $(-0.122 \pm 0.001)$ than straight trajectory $(-0.073 \pm$ $0.001)$ averaged across tire pressures $(p=0.001)$. The confidence intervals (Figure 4) and effect sizes (Table 2) indicate significant differences between all inflation levels. Effect sizes, represented as Cohen $d$, can be interpreted as the average percentile standing of the tested configuration relative to the 100 percent inflation level. As an example, the effect size of 2.7 places the mean of the 55 psi configuration over the 99th percentile of the 75 psi torque distribution. Tires inflated to 75 percent had 10 percent greater decelerations than 100 percent inflation in straight trajectories and 14 percent greater decelerations in turning trajectories. In addition, 50 percent inflation had 18 percent greater decelerations than 100 percent inflation during straight trajectories and 28 percent greater decelerations during turning trajectories.

Tables $\mathbf{3}$ and $\mathbf{4}$ and Figure $\mathbf{5}$ show the MWC decelerations, related resistive forces, and torques with two masses $\times$ two weight distributions. Analysis of deceleration values indicated that values across both mass and weight distributions were significantly different for both trajectories $(p<0.001)$. In straight trajectories, MWCs with a $17.6 \mathrm{~kg}$ mass had, on average, 2 percent greater decelerations than those with a $12.1 \mathrm{~kg}$ mass, and MWCs with 55 percent weight of their DWs had, on average, 17 percent greater decelerations. In turning trajectories, 
Table 2.

Deceleration values in each coast-down test by using test dummy with default configuration.

\begin{tabular}{|c|c|c|c|c|c|}
\hline Tire Pressure (psi) & Trajectory & Mean \pm SD $\left(\mathrm{m} / \mathrm{s}^{2}\right)$ & CV (\%) & \% Increase & Cohen $d$ \\
\hline$\overline{75}$ & Straight & $-0.067 \pm 0.002$ & 3.2 & - & - \\
\hline 55 & Straight & $-0.074 \pm 0.003$ & 4.0 & 10.4 & 2.75 \\
\hline 75 & Turning & $-0.107 \pm 0.005$ & 5.3 & - & - \\
\hline 55 & Turning & $-0.122 \pm 0.002$ & 2.5 & 14.0 & 3.94 \\
\hline
\end{tabular}

$\mathrm{CV}=$ coefficient of variation, $\mathrm{SD}=$ standard deviation.

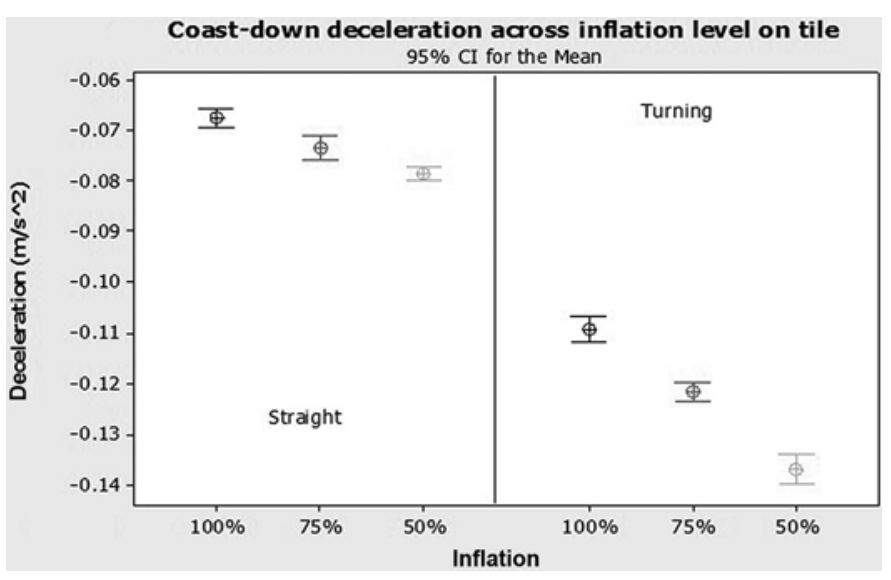

Figure 4.

Comparison of deceleration values for three tire inflations during straight and turning trajectories on tile. $\mathrm{Cl}=$ confidence interval.

MWCs with a greater mass had 11 percent greater decelerations, while MWCs with 70 percent weight of their DWs had 32 percent greater decelerations. Differences between the base configuration of the ultralight MWC (12.1 kg and 70\%) and the other configurations are indicated by percent differences and Cohen $d$ effect sizes (Table 3). All effect sizes can be considered as large [30]. As a reference, the effect size of 0.63 places the mean of the $17.6 \mathrm{~kg}$ and 70 percent configuration value at the 74th percentile of the reference configuration-in this case, $12.1 \mathrm{~kg}$ and 70 percent configuration.

\section{DISCUSSION}

The described test method showed good repeatability $(\mathrm{CV} \leq 5.3 \%)$ and reliability $(\mathrm{ICC}=0.96)$ during both straight and fixed-wheel turning maneuvers. Analysis indicated that three trials would offer sufficient repeatability using the Spearman-Brown Prophecy Formula. This repeatability is consistent with that of other freewheeling coast-down tests. In Coutts' study, the decelerations during the first six trials were determined with an average CV of 7.1 percent on a hardwood floor [31]. Comparing the decelerations across studies is difficult since different coast-down studies used different wheelchair frames [14-16], wheels [13,16], and ground types $[19,21,32]$. However, with similar weight distribution (30\% loading on casters), our deceleration values had a similar range as Sauret et al. (from -0.05 to $-0.25 \mathrm{~m} / \mathrm{s}^{2}$ ) on a hard, smooth surface [16]. To validate the predicting model for the rolling resistance, Sauret et al. reported an acceptable accuracy from their mathematical equation (standard error of the estimate was 4.4 and $3.9 \mathrm{~N}$, respectively) [16].

Resistive losses affect the overall propulsion effort of the user because they represent the energy that must be returned to the MWC by users as they maneuver. These resistive forces and torques are ever-present, and in fact, are needed to maintain contact with the ground while maneuvering. The magnitudes of the forces and torques measured in this study were not very high, with resistive forces between 6 and $7 \mathrm{~N}$ and resistive torques between 3 $1 / 2$ and $51 / 5 \mathrm{~N} \bullet \mathrm{m}$. However, their cumulative effects over the course of the day can be significant. Research indicates that MWC users travel about $1 \mathrm{~km}$ per day in about 90 bouts of mobility [20]. When maneuvering an MWC with greater resistive losses, the user will have to exert greater effort within a bout of mobility and cumulatively will expend more energy throughout the day. Because maneuvering MWCs includes both straight and turning trajectories, a review of the respective resistive losses during both trajectories should be considered. 
JRRD, Volume 52, Number 7, 2015

Table 3.

Manual wheelchair decelerations across two masses by two weight distributions during straight and turning trajectories.

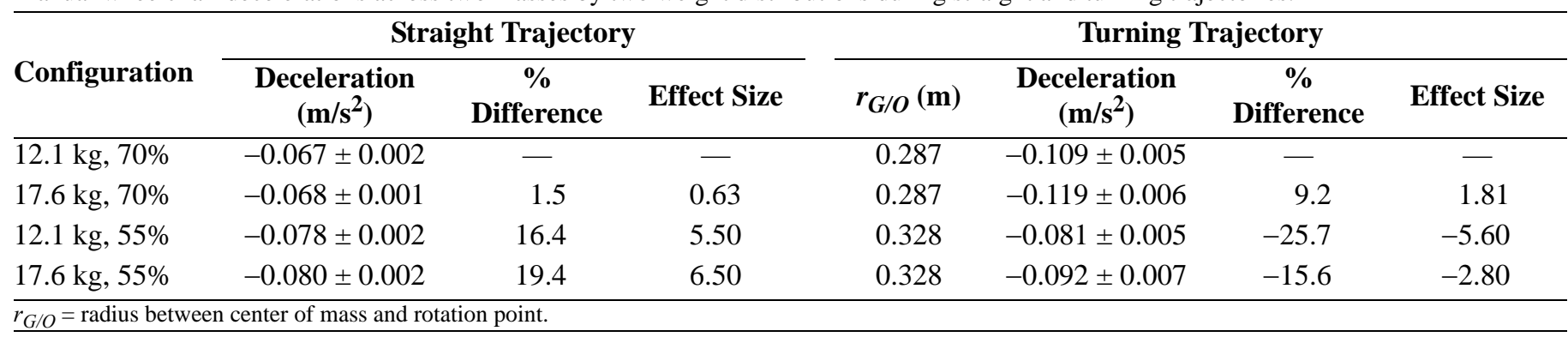

Table 4.

Resistive forces and torques across configurations during straight and turning trajectories.

\begin{tabular}{lcc}
\hline Configuration & $\begin{array}{c}\text { Straight Trajectory: } \\
\text { Resistive Force (N) }\end{array}$ & $\begin{array}{c}\text { Turning Trajectory: } \\
\text { Resistive Torque } \\
\mathbf{( N \bullet m ) ~}\end{array}$ \\
\hline $12.1 \mathrm{~kg}, 70 \%$ & $-6.096 \pm 0.181$ & $-4.715 \pm 0.216$ \\
$17.6 \mathrm{~kg}, 70 \%$ & $-6.518 \pm 0.096$ & $-5.338 \pm 0.269$ \\
$12.1 \mathrm{~kg}, 55 \%$ & $-7.083 \pm 0.181$ & $-3.530 \pm 0.219$ \\
$17.6 \mathrm{~kg}, 55 \%$ & $-7.666 \pm 0.193$ & $-4.210 \pm 0.320$ \\
\hline
\end{tabular}

The fixed-wheel turn highlighted the resistive losses caused by tire scrub. Results showed that the decelerations were significantly higher during turning than during straight coast-down tests. Since resistive forces during turning include tire scrub and rolling resistance, these results illustrate that more resistive loss is associated with turning than with propelling in straight directions. The results also highlighted the influence of tire inflation on resistive loss during turning compared with during straight trajectories. With the increased contact area of a deflated tire, the results demonstrated that even a 25 percent decrease in tire inflation has an adverse effect on resistive losses. Moreover, the results indicated that inflation had a greater effect on resistive loss during scrubbing than during rolling.

Prior studies have reported that tire type and pressure influence rolling resistance and thus can change propulsion effort $[3,10,13]$. Pneumatic tires have been shown to have lower rolling resistance than solid tires [10,13]. Moreover, pneumatic tires with different inflation levels have been shown to have different rolling resistances [3]. By using the same type of pneumatic tires, Sawatzky et al. found that a tire inflated to 100 percent had significantly less rolling resistance than tires inflated to 50 percent, but did not find a difference comparing tires inflated to 100

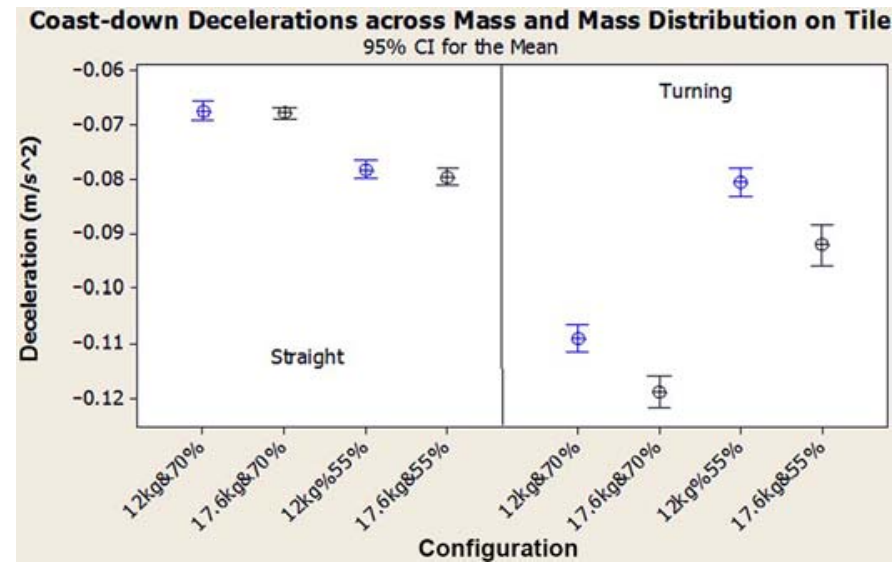

Figure 5.

Comparison of deceleration values for four configurations during straight and turning trajectories on tile. $\mathrm{Cl}=$ confidence interval.

and 75 percent [3]. Our results both corroborate and extend these results to add to the knowledge about tire inflation. During straight trajectories, MWC deceleration at 75 and 50 percent inflation levels were 5 and 16.3 percent greater than that at 100 percent inflation, respectively. However, during turning, inflation levels had more influence, with deceleration increasing by 14 and 28 percent at 75 and 50 percent inflation levels, respectively. Significant differences in decelerations were found across all three inflation levels with large effect sizes. The results were also consistent with a previous study that indicated propelling an MWC through a $90^{\circ}$ turn with one hand required 20 percent higher propulsion work than straight propulsion on carpet [33]. Clinically, these results illustrated that turning effort will increase even with slightly deflated tires, thus emphasizing the importance of periodic wheelchair tire maintenance. With respect to measuring resistive losses, these results demonstrate that 
considering both straight and turning maneuvers can improve the sensitivity for differentiating resistive forces across wheelchair configurations.

The results indicate that weight distribution had a greater influence on resistive forces than mass in both straight and turning trajectories. In addition, the effect of weight distribution on resistive loss varied according to the trajectory of motion. This result is consistent with those of Bascou et al., who studied rolling resistance of different wheelchair configurations and reported a 52 percent increase in the decelerations when the loads on the casters varied from 29 to 64 percent using the same wheelchair mass [14]. Similar observations were made by Sauret et al., who speculated that decelerations would continually increase as the distribution of total mass on the front wheels increased [16]. These studies underlined the significant influence of weight distribution on the resistive force in straight trajectories, and our results extend these findings to describe the effect of weight distribution on resistive torque in turning. According to our results, the frictional force of the chairs with 55 percent weight on the DWs were 17 percent greater than those with 70 percent weight distribution in a straight trajectory. In distinction, the chairs with a 70 percent weight distribution had resistive torques that were 30 percent greater than those with a 55 percent weight distribution during turning. This is an important finding that can be explained by the different sources of resistive loss in straight and turning trajectories (Figure 2). When traveling straight, resistive forces are due to the rolling resistance of the casters and DWs. The results show that a greater weight distribution on the DWs reduces the system's rolling resistance. In a fixed-wheel turn, resistive torques are due to rolling resistance of the casters and the rolling DWs as well as the losses caused by tire scrub. Tire scrub happens when a wheel rotates on the rolling surface during a turning maneuver. The results showed that the greater load on the DWs due to moving the axle forward results in a greater resistive loss because of the heightened tire scrub.

Current clinical practice advocates for a forward axle position based on its advantage from a biomechanical perspective [34-35]. Pitch stability is rightly identified as an important consideration when determining how anterior the axle should be positioned. Pitch stability decreases because a forward axle position shifts the CoM rearward with a concomitant increase in weight on the DWs. However, our results demonstrate that the increase in biomechanical advantage also comes at the cost of increased turning resistance. Like many MWC configuration changes, axle position affects multiple performance variables both negatively and positively. As a result, clinicians should consider this trade-off when adjusting MWCs. In particular, propulsion effort should be evaluated because MWC users perform turning maneuvers on common surfaces, including tile and carpet.

\section{LIMITATIONS}

The resistive forces of an occupied wheelchair depend on a number of factors, including total system mass, the surface on which the wheelchair is maneuvering, the speed at which coast-down begins, the radius of curvature of turns, tire type, and DW and caster diameters. Therefore, any test method that seeks to characterize resistive forces includes variables that may affect the results, and the test method described here is no different. The test method described in this article used a consistent $76 \mathrm{~kg}$ mass of the occupant dummy and speeds that are reflective of everyday mobility. It also used a single type of tire and single sizes of DWs and caster wheels in order to assess the influences of the independent variables, namely inflation level, MWC mass, and mass distribution. Assessing the influence of other variables is needed to fully characterize resistive forces during MWC maneuvers.

Distinct from straight trajectories, all curvilinear trajectories require an external force to maintain. This test method used a fixed-wheel turn in which one DW was locked. The wheel lock applies an internal system force but an external centripetal force is also present at the contact point between the DWs and the floor surface that prevents the MWC from moving tangentially to the radius of curvature or slipping on the floor surface. Other means to constrain curvilinear trajectories exist and also require internal or external forces. For example, a tension member (such as a rope or bar) will apply an external force that will work in tandem with the resistive forces to allow the MWC to maintain a turning trajectory. Another approach includes fixing the casters at a specific angle to the frame, which adds an internal system force that works with the external centripetal forces at the ground interface. We chose an approach that limits external centripetal forces to those at the DW-surface interface in order to simplify the test methodology. This methodological decision results in a test that includes the effects of tire scrub as resistive torques using a tight turning radius. 


\section{CONCLUSIONS}

The dominant resistive forces of a rolling MWC result from rolling resistance and tire scrub. Multiple researchers have measured coast-down in straight trajectories, yet turning maneuvers must also be considered to characterize resistive loss. The described coast-down test method, including straight and fixed-wheel turns, offers a simple and reliable method for assessing MWC resistive loss. This method could easily be applied to evaluate the influence of different MWC configurations, tires, and rolling surfaces. The results of this study confirmed that higher resistive loss exists (1) during turning compared with straight trajectories and (2) with use of underinflated pneumatic tires. In addition, the results indicate that weight distribution has a greater effect on resistive losses than a $5.5 \mathrm{~kg}$ increase in MWC mass and that this effect varies between straight and turning maneuvers. Based on the results of this and previous studies, clinicians and MWC users should carefully consider the effect of MWC resistive loss while selecting or configuring an MWC. Researchers should also consider how differences in resistive losses during turning maneuvers affect propulsion effort. Based on prior research, a biomechanical benefit exists with a forward axle position. However, the concomitant increased weight on the DWs can increase resistive torques during turning. Additional research is needed to define axle positions and weight distributions that optimize propulsion effort during turning trajectories by balancing the biomechanical benefit against the increased resistive loss due to tire scrub.

\section{ACKNOWLEDGMENTS}

\author{
Author Contributions: \\ Study concept and design: J. Lin, M. Huang, S. Sprigle. \\ Acquisition of data: J. Lin. \\ Analysis and interpretation of data: J. Lin, M. Huang, S. Sprigle. \\ Drafting of manuscript: J. Lin, M. Huang. \\ Critical revision of manuscript for important intellectual content: \\ S. Sprigle. \\ Statistical analysis: J. Lin. \\ Obtained funding: S. Sprigle. \\ Study supervision: S. Sprigle.
}

Financial Disclosures: The authors have declared that no competing interests exist. TiLite had no input on the publication of this study.

Funding/Support: This material was based on work supported by the Mobility Rehabilitation Engineering Research Center, National Institute on Disability, Independent Living, and Rehabilitation Research of the U.S. Department of Health and Human Services (grant 90RE5000-01-00).

Additional Contributions: We are grateful for the generosity of TiLite, who donated the wheelchair used in this study. We would like to thank Howard Liles for consulting on the data analysis and Russell Taylor for his work in modifying some of the hardware for the study.

Disclaimer: The opinions contained in this article are those of the grantee and do not necessarily reflect those of the U.S. Department of Education.

\section{REFERENCES}

1. Koontz AM, Cooper RA, Boninger ML, Yang Y, Impink BG, van der Woude LH. A kinetic analysis of manual wheelchair propulsion during start-up on select indoor and outdoor surfaces. J Rehabil Res Dev. 2005;42(4):447-58.

[PMID:16320141]

http://dx.doi.org/10.1682/JRRD.2004.08.0106

2. Caspall JJ, Seligsohn E, Dao PV, Sprigle S. Changes in inertia and effect on turning effort across different wheelchair configurations. J Rehabil Res Dev. 2013;50(10): 1353-62. [PMID:24699971]

http://dx.doi.org/10.1682/JRRD.2012.12.0219

3. Sawatzky BJ, Kim WO, Denison I. The ergonomics of different tyres and tyre pressure during wheelchair propulsion. Ergonomics. 2004;47(14):1475-83. [PMID:15697064] http://dx.doi.org/10.1080/00140130412331290862

4. Boninger ML, Dicianno BE, Cooper RA, Towers JD, Koontz AM, Souza AL. Shoulder magnetic resonance imaging abnormalities, wheelchair propulsion, and gender. Arch Phys Med Rehabil. 2003;84(11):1615-20.

[PMID:14639560] http://dx.doi.org/10.1053/S0003-9993(03)00282-X

5. van der Woude LH, Dallmeijer AJ, Janssen TW, Veeger D. Alternative modes of manual wheelchair ambulation: An overview. Am J Phys Med Rehabil. 2001;80(10):765-77. [PMID:11562560] http://dx.doi.org/10.1097/00002060-200110000-00012

6. van der Woude LH, van Kranen E, Ariëns G, Rozendal RH, Veeger HE. Physical strain and mechanical efficiency in hubcrank and handrim wheelchair propulsion. J Med Eng Technol. 1995;19(4):123-31. [PMID:8544207] http://dx.doi.org/10.3109/03091909509012418

7. Thacker JG, Foraiati K. Ride comfort. In: Thacker JG, editor. Wheelchair mobility: Improved wheelchair and seating design, summary of activities February 1991-January 1992. Charlottesville (VA): University of Virginia Rehabilitation Engineering Center; 1991. p. 27-33.

8. van der Woude LH, Geurts C, Winkelman H, Veeger HE. Measurement of wheelchair rolling resistance with a handle bar push technique. J Med Eng Technol. 2003;27(6): 
249-58. [PMID:14602516]

http://dx.doi.org/10.1080/0309190031000096630

9. Brubaker CE. Wheelchair prescription: An analysis of factors that affect mobility and performance. J Rehabil Res Dev. 1986;23(4):19-26. [PMID:3820118]

10. Kauzlarich JJ, Thacker JG. Wheelchair tire rolling resistance and fatigue. J Rehabil Res Dev. 1985;22(3):25-41. [PMID:3835263]

http://dx.doi.org/10.1682/JRRD.1985.07.0025

11. Gordon J, Kauzlarich JJ, Thacker JG. Tests of two new polyurethane foam wheelchair tires. J Rehabil Res Dev. 1989;26(1):33-46. [PMID:2918486]

12. de Groot S, Vegter RJ, van der Woude LH. Effect of wheelchair mass, tire type and tire pressure on physical strain and wheelchair propulsion technique. Med Eng Phys. 2013; 35(10):1476-82. [PMID:23642660]

http://dx.doi.org/10.1016/j.medengphy.2013.03.019

13. Kwarciak AM, Yarossi M, Ramanujam A, Dyson-Hudson TA, Sisto SA. Evaluation of wheelchair tire rolling resistance using dynamometer-based coast-down tests. J Rehabil Res Dev. 2009;46(7):931-38. [PMID:20104415] http://dx.doi.org/10.1682/JRRD.2008.10.0137

14. Bascou J, Sauret C, Pillet H, Vaslin P, Thoreux P, Lavaste F. A method for the field assessment of rolling resistance properties of manual wheelchairs. Comput Methods Biomech Biomed Engin. 2013;16(4):381-91.

[PMID:22260153]

http://dx.doi.org/10.1080/10255842.2011.623673

15. Hoffman MD, Millet GY, Hoch AZ, Candau RB. Assessment of wheelchair drag resistance using a coasting deceleration technique. Am J Phys Med Rehabil. 2003;82(11): 880-89, quiz 890-92. [PMID:14566157] http://dx.doi.org/10.1097/01.PHM.0000091980.91666.58

16. Sauret C, Bascou J, de Saint Rémy N, Pillet H, Vaslin P, Lavaste F. Assessment of field rolling resistance of manual wheelchairs. J Rehabil Res Dev. 2012;49(1):63-74. [PMID:22492338] http://dx.doi.org/10.1682/JRRD.2011.03.0050

17. Pacejka H. Tire and vehicle dynamics. 2nd ed. Warrendale (PA): SAE International; 2006.

18. Kauzlarich JJ, Bruning T, Thacker JG. Wheelchair caster shimmy and turning resistance. J Rehabil Res Dev. 1984; 21(2):15-29. [PMID:6530672]

19. Frank TG, Abel EW. Measurement of the turning, rolling and obstacle resistance of wheelchair castor wheels. J Biomed Eng. 1989;11(6):462-66. [PMID:2811344] http://dx.doi.org/10.1016/0141-5425(89)90040-X

20. Sonenblum SE, Sprigle S, Lopez RA. Manual wheelchair use: Bouts of mobility in everyday life. Rehabil Res Pract. 2012;2012:753165. [PMID:22848837] http://dx.doi.org/10.1155/2012/753165
21. Sauret C, Vaslin P, Lavaste F, de Saint Remy N, Cid M. Effects of user's actions on rolling resistance and wheelchair stability during handrim wheelchair propulsion in the field. Med Eng Phys. 2013;35(3):289-97. [PMID:23200111] http://dx.doi.org/10.1016/j.medengphy.2012.05.001

22. ISO 7176-11:2012. Wheelchairs-Part 11: Test dummies. Geneva (Switzerland): International Organization for Standardization; 2012.

23. American National Standards Institute; Rehabilitation Engineering and Assistive Technology Society of North America. Wheelchairs: Determination of coefficient of friction of test surfaces. Bethesda (MD): Rehabilitation Engineering and Assistive Technology Society of North America; 1991.

24. Centers for Medicare and Medicaid Services. National coverage determination (NCD): Mobility assistive equipment (MAE) (280.3); Independence iBOT 4000 mobility system (280.15); Durable medical equipment reference list (280.1) [Internet]. Washington (DC): Centers for Medicare and Medicaid Services; 2005 [cited 2015 Sep 18]. Available from: http://www.cms.gov/medicare-coverage-database/ search/advanced-search

25. Eicholtz MR, Caspall JJ, Dao PV, Sprigle S, Ferri A. Test method for empirically determining inertial properties of manual wheelchairs. J Rehabil Res Dev. 2012;49(1):51-62. [PMID:22492337] http://dx.doi.org/10.1682/JRRD.2011.03.0045

26. du Bois JL, Lieven NA, Adhikari S. Error analysis in trifilar inertia measurements. Exp Mech. 2009;49(4):533-40. http://dx.doi.org/10.1007/s11340-008-9142-4

27. Hou Z, Lu Y, Lao Y, Liu D. A new trifilar pendulum approach to identify all inertia parameters of a rigid body or assembly. Mechanism Mach Theory. 2009;44(6):1270-80. http://dx.doi.org/10.1016/j.mechmachtheory.2008.07.004

28. Oyster ML, Karmarkar AM, Patrick M, Read MS, Nicolini $\mathrm{L}$, Boninger ML. Investigation of factors associated with manual wheelchair mobility in persons with spinal cord injury. Arch Phys Med Rehabil. 2011;92(3):484-90. [PMID:21353831] http://dx.doi.org/10.1016/j.apmr.2010.09.025

29. Hofstad M, Patterson PE. Modelling the propulsion characteristics of a standard wheelchair. J Rehabil Res Dev. 1994; 31(2):129-37. [PMID:7965869]

30. Cohen J. Statistical power analysis for the behavioral sciences. 2nd ed. Hillsdale (NJ): L. Earlbaum Associates; 1988.

31. Coutts KD. Dynamic characteristics of a sport wheelchair. J Rehabil Res Dev. 1991;28(3):45-50. [PMID:1880749] http://dx.doi.org/10.1682/JRRD.1991.07.0045

32. Vinet A, Bernard PL, Ducomps C, Selchow O, Le Gallais D, Micallef JP. A field deceleration test to assess total wheelchair resistance. Int J Rehabil Res. 1998;21(4):397-401. [PMID:9926355] http://dx.doi.org/10.1097/00004356-199812000-00007 
33. ASTM F1951-14. Standard specification for determination of accessibility of surface systems under and around playground equipment. West Conshohocken (PA): ASTM International; 2014.

34. Hughes CJ, Weimar WH, Sheth PN, Brubaker CE. Biomechanics of wheelchair propulsion as a function of seat position and user-to-chair interface. Arch Phys Med Rehabil. 1992;73(3):263-69. [PMID:1543431]

35. Freixes O, Fernández SA, Gatti MA, Crespo MJ, Olmos LE, Rubel IF. Wheelchair axle position effect on start-up propulsion performance of persons with tetraplegia. J Rehabil Res Dev. 2010;47(7):661-68. [PMID:21110262] http://dx.doi.org/10.1682/JRRD.2009.09.0146

Submitted for publication October 14, 2014. Accepted in revised form May 20, 2015.
This article and any supplementary material should be cited as follows:

Lin J, Huang M, Sprigle S. Evaluation of wheelchair resistive forces during straight and turning trajectories across different wheelchair configurations using freewheeling coast-down test. J Rehabil Res Dev. 2015; 52(7):763-74.

http://dx.doi.org/10.1682/JRRD.2014.10.0235

ResearcherID/ORCID: Jui-Te Lin, MS: K-8908-2015; Morris Huang, BSME: K-9311-2015; Stephen Sprigle, PhD, PT: 0000-0003-0462-0138

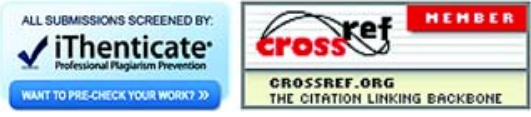

